\title{
Parametric Modeling of Components for Selection and Specification of Hybrid Vehicle Drivetrains
}

\author{
Theo Hofman*, Maarten Steinbuch*, Roëll van Druten**, Alex Serrarens**
}

\begin{abstract}
Drivetrain hybridization implies adding a secondary power source (electric machine/battery) to a primary power source (engine/filled fuel tank) in order to improve: fuel economy, emissions, drivability (performance), comfort and safety. Designing a hybrid vehicle drivetrain fulfilling the required vehicle driving functions is therefore a complex task. Many researchers have put effort formulating and developing overall hybrid drivetrain analysis, design and optimization models including top-level vehicle control strategy for optimal fuel economy. This paper seeks to investigate the possibility of overall model simplification for the hybrid drivetrain system including the control strategy. This is performed by describing the component efficiencies and control rules with only a few characteristic parameters that capture the total systems fuel efficiency with sufficient accuracy $(\sim 1 \%)$. Using these parameters the modeling and simulation process can be done very quickly. The method has been demonstrated on a series -, a parallel - and a series-parallel hybrid drivetrain with specified component technologies, vehicle parameters and drive cycle. The fuel economy and control strategy results are compared with Simulink/Advisor and Dynamic Programming.
\end{abstract}

Keywords: Hybrid Electric Vehicles, System Design Optimization, Modeling and Simulation, Hybrid Strategy, Energy Efficiency, Energy Consumption, Power train, Transmission, Optimal control.

\section{INTRODUCTION}

Ongoing emission legislation and increasing fuel prices pursue many leading vehicle manufactures, and their suppliers to put effort in developing and manufacturing new efficient though cost-effective drivetrain technologies. On nowadays passenger vehicle market, hybrid vehicles are readily available, e.g., the Honda Civic IMA, Toyota Prius, Ford Escape, Lexus RX400h, etc. All these vehicles fulfill almost the same hybrid functions, e.g., energy recuperation during braking, motor-assisting, engine off during standstill. Despite of this, their drivetrain topology, transmission technology and control are completely different. The objectives of a hybrid drivetrain are to some extend improving the driving functions of a vehicle: fuel economy, emissions, drivability (performance), comfort and safety. Due to the complexity of hybrid vehicle drivetrains, the design of topologies, component technologies and the control strategy forms a considerable challenge for engineers. Therefore, many researchers have devoted their attention to develop different hybrid drivetrain modeling and simulation tools [1-6]. The tools are usually based on predefined drivetrain topologies, specific component technologies

* Technische Universiteit Eindhoven, P.O.Box 513, $5600 \mathrm{MB}$ Eindhoven, The Netherlands, e-mail:t.hofman@tue.nl; m.steinbuch@tue.nl

** Drivetrain Innovations B.V., Horsten 1, 5612 AX Eindhoven, The Netherlands, e-mail:druten@dtinnovations.nl; serrarens@dtinnovations.nl and control strategies. In [4-5] a more flexible modeling and simulation tool (QSS toolbox) is discussed, with which user-defined drivetrain topologies can be build quite easily. In [6-7] the research is focused on developing system design tools for optimizing component sizes and vehicle design parameters, whereby ADVISOR [2] is used as vehicle modeling and simulation platform. Other system design optimization approaches use globally optimal control strategy based on Dynamic Programming (DP) [8]. However, an integral system design approach is usually characterized by large computational times, complex design problem (optimization) formulations, multiple subsystem simulations, non-smooth or non-continuous models. In addition, insights into the design problem at hand are lost when a single final design proposal is presented as a result of a complex integral design process. Interactions between the different drivetrain components, topology and control are then difficult to investigate.

\section{OBJECTIVES AND APPROACH}

This paper presents a "modeling approach" in characterizing the component technologies in order to select topologies and for designing the control strategy of hybrid vehicle drivetrains (see Fig. 1 for an overview). Thereby, a generic "hybrid topology model" is introduced, whereby the main power sources, i.e., Primary power source (P) (engine), Secondary power source (S) (battery/electric machine) and Transmission 
technology (T) (depicted as "black box models") are modeled by simplified parametric "power-based efficiency fit functions". If an affine relationship is assumed, then the input power $P_{\text {in }}$ as a function of the output power $P_{\text {out }}$ becomes $P_{\text {in }}=c_{1} \cdot P_{\text {out }}+c_{0}$. The static power losses are represented by $c_{0}$ and the reciprocal of the inner efficiency by $c_{1}$ respectively. Furthermore, the variable $P_{\max }$ represents the output power limitation of the component. In order to capture the high power-loss effects of the engine a second order approximation gives better-fit results [9]. The operation points of $\mathrm{P}, \mathrm{S}$ and $\mathrm{T}$ determine the characteristic parameters $\left(c_{1}, c_{0}\right)$ of the power-based efficiency functions. The main assumptions to speed up the modeling/simulation process are the operation points determined by driving a vehicle over a drive cycle: (i) during regenerative braking and pure electric driving have been used to fit linear functions describing the $\mathrm{S}$ efficiency. If $\mathrm{S}$ is coupled at engine-side of the transmission, then $S$ is operated at the highest efficiency points by selecting the optimal transmission ratios. If $S$ is coupled at the wheel-side, then the transmission ratio is fixed. (ii) With a battery power equal to zero has been used to fit a linear function describing the $\mathrm{T}$ efficiency, whereby $\mathrm{P}$ is operated at the highest efficiency points. It will be shown, that operating $\mathrm{S}$ during hybrid driving modes has effect on the transmission efficiency, but that the change in transmission efficiency has a negligible effect on the overall fuel economy. The modeling approach discussed in this paper is a step forwards in developing a quick modeling and simulation tool for component sizing and topology selection whereby the fuel economy is calculated very quickly and with sufficient accuracy. Thereby, a target is to find answers to the underlying research questions:

(i) Can the component efficiency models and the control model be described with sufficient accuracy by a limited set of characteristic parameters?

(ii) What is the influence of the drivetrain component technology and the topology on the fuel economy and emissions?

The first research question studies the influence of the operation points on the component efficiency. Thereby, ADVISOR and DP are used as reference "control models/algorithms". In addition, a novel "Rule-Based Energy Management Strategy" (RB EMS) is used with which the fuel economy and control

\section{REFERENCE MODELS} TOPOLOGY, COMPONENTS, CONTROL

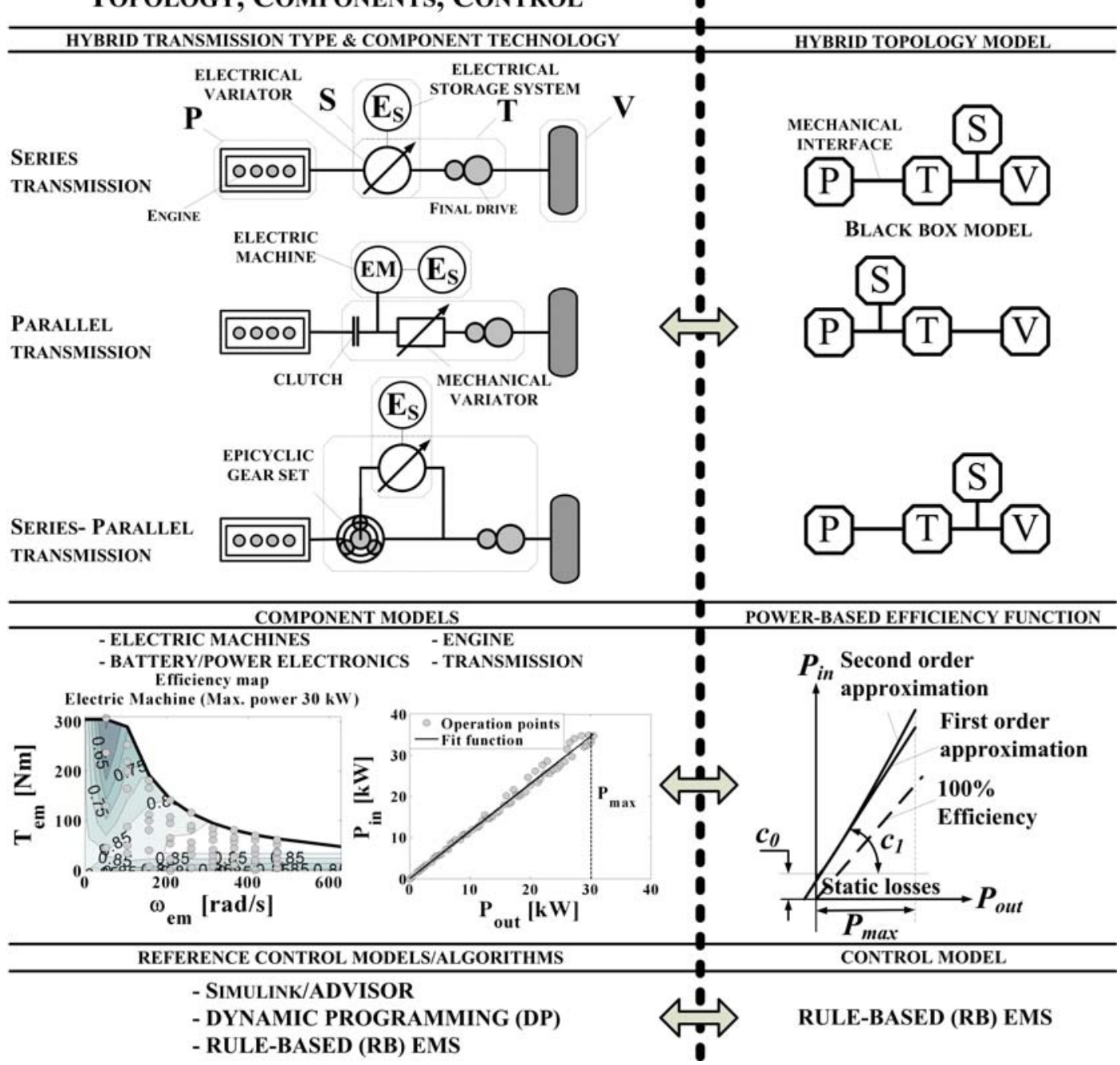

Fig. 1 Classification overview of different hybrid drivetrains and modeling approach 
strategy can be calculated very quickly and with the same accuracy as DP $(\sim 1 \%)$ (see [10]). The second research question studies if a generic hybrid topology model can be used independently on the type of hybrid transmission. Therefore, the influence of three typical different hybrid drivetrain topologies, i.e., "series", "parallel" and a "series-parallel" hybrid transmission with different component technologies on fuel economy and emissions is investigated. The maximum vehicle power specification consisting of the engine and the electric machine power is kept constant, such that the acceleration performance of the vehicle is not compromised. Furthermore, for comparison the main vehicle parameters and the drive cycle describing the vehicle load are also kept constant.

The topology - and the rule-based control model are discussed in the Sections 3 and 4 respectively. The simulation results of the topology and the parametric component modeling study are discussed in Section 5. Finally, the conclusions are described in Section 6.

\section{HYBRID TOPOLOGY MODEL}

A drivetrain topology defines the possible connections and puts constraints on the transmission ratios between $\mathrm{P}, \mathrm{S}$, and $\mathrm{V}$. For the series - and the series-parallel transmission the advantage is that $S$ is integrated with $\mathrm{T}$. However, looking at a higher abstraction level for both transmission types $\mathrm{S}$ is functionally coupled to the wheel-side of the transmission, as is shown in Fig. 1 (top-right). Thereby, the intrinsic functions for $\mathrm{S}$ are defined as performing recuperation of brake energy (BER) and propulsion only by $\mathrm{S}$ while $\mathrm{P}$ is shut-off (eliminating the engine drag - and friction losses). In addition, for the parallel and series-parallel transmission Charging $(\mathrm{CH})$ or Motor-Assisting (MA) during driving is possible with S. In case of the series - or the series-parallel transmission this will or can also be done with the electric machine connected at the engine-side respectively. However, most of the charged energy with the electric machine at the engine-side is directly transmitted to electric machine at the wheel side (avoiding additional battery losses). In Section 4 the hybrid modes will be discussed in more detail. For the parallel transmission $\mathrm{S}$ is connected at the engine-side of $\mathrm{T}$. The variator of the series - and the parallel transmission consists respectively of two electric machines and a push-belt Continuously Variable Transmission (CVT). One of the major advantages of the series transmission is the infinitely variable transmission ratio. Thereby, it is possible to operate the engine and the generator intermediately, but continuously at its highest efficiency point(s). However, at higher requested vehicle loads, the transmission losses of the electrical variator are typically larger than compared to a mechanical variator. The CVT losses in the parallel transmission are lower at higher vehicle loads, but due to the overdrive constraint not all optimal operating points of the engine can be reached. The series-parallel transmission combines the electrical - and mechanical paths with its advantages, which consists of a planetary gear set combined with two electric machines, which form the electrical variator part of $\mathrm{T}$. The advantages of a series-parallel transmission, compared to a series transmission are:

- The transmission efficiency is higher, because most of the power is transmitted over the mechanical branch;

- An electrical variator with a lower maximum power specification can be used.

However, a disadvantage is the possible occurrence of re-circulation of power flow thereby reducing the transmission efficiency. The operation of the variator and the influence of the battery power on the power flows and the overall efficiency are discussed in more detail in [11].

\section{CONTROL MODEL}

\subsection{Energy Management Optimization Problem}

The optimization problem is finding the optimal control power flow $P_{s}(t)$ of the power source $\mathrm{S}$ given a certain power demand at the wheels $P_{v}(t)$, while the fuel energy, denoted as the variable $J$, over a certain drive cycle with time length $t_{f}$ is minimized subjected to several constraints, i.e.,

$$
J\left(E_{s}, P_{s}, t\right)=\min _{\mathrm{P}_{\mathrm{s}}} \int_{0}^{t_{f}} P_{f}\left(E_{s}, P_{s}, t\right) \cdot d t,
$$

subject to $\vec{h}=0, \vec{g} \leq 0$, where the fuel power $P_{f}$ is the product of the fuel rate $(\mathrm{g} / \mathrm{s})$ and the lower heating value $h_{l v}(\mathrm{~J} / \mathrm{g})$ for fuel. The main constraints are energy conservation balance of $E_{s}$ over the drive cycle, constraints on the power $P_{s}$ and the energy $E_{s}$ :

$$
\begin{aligned}
& h_{1}:=\Delta E_{s}\left(t_{f}\right)=E_{s}\left(t_{f}\right)-E_{s}(0)=\int_{0}^{t_{f}} P_{s}(t) \cdot d t=0, \\
& g_{1,2}:=P_{s, \text { min }} \leq P_{s}(t) \leq P_{s, \max }, \\
& g_{3,4}:=E_{s, \text { min }} \leq E_{s}(t) \leq E_{s, \text { max }} .
\end{aligned}
$$

\subsection{The Rule-Based Energy Management Strategy}

The control model used in this paper is based on a Rule-Based (RB) Energy Management Strategy (EMS) as is described in [10]. Thereby, the hybrid drivetrain can be operated in certain distinct driving modes. In Fig. 2 , a block diagram is shown for the power distribution between the different energy sources, i.e., fuel tank with stored energy $E_{f}$, power source $S$ with stored energy $E_{s}$ and the vehicle driving over a drive cycle represented by a required energy $E_{v}$. The efficiencies of the fuel combustion in the engine, the storage and electric motor $\mathrm{S}$, and the Transmission (T) are described by the variables $\eta_{p}, \eta_{s}$, and $\eta_{t}$ respectively. The energy exchange between the fuel tank, $\mathrm{S}$ and the vehicle can be performed by different driving modes. The engine power at the crankshaft is represented by $P_{p}$. The power demand at the wheels $\left(P_{v}\right)$, and the power flow to and from the power source $\mathrm{S}\left(P_{s}\right)$ determines which driving 
mode is active. The following operation modes are defined:

- M: Motor only mode, the vehicle is propelled only by the electric motor and the battery storage supply $\mathrm{S}$ up to a certain discharge power level $P^{o}{ }_{M}$, which is not necessary equal to the minimum discharging power $P_{s, \min }$. The engine is off, and has no drag -, and idle losses.

- BER: Brake Energy Recovery mode, the brake energy is recuperated up to the maximum generative power limitation $P_{s, \max }$, and stored into the accumulator of $\mathrm{S}$. The engine is off, and has no drag -, and idle losses.

- $\mathrm{CH}$ : Charging mode, the instantaneous engine power is higher than the power needed for driving. The redundant energy is stored into the accumulator of $\mathrm{S}$.

- MA: Motor-Assisting mode, the engine power is lower than the power needed for driving. The engine power is augmented by power from $S$.

- E: Engine only mode, only the engine power is used for propulsion of the vehicle. $\mathrm{S}$ is off, and generates no losses.

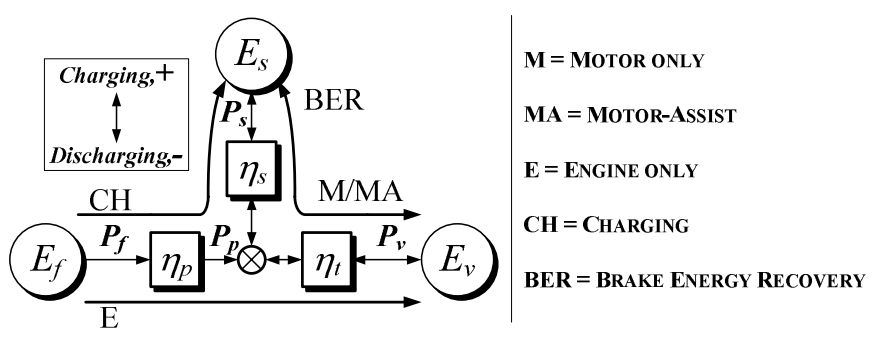

Fig. 2 Power flows for different hybrid driving modes. $\mathrm{S}$ is connected at the engine-side of the transmission.

During the M, and the BER mode the engine is off, and as a consequence uses no fuel. This is also referred to as the Idle-Stop (IS) mode. In order to fulfill the integral energy balance constraint over the drive cycle, the energy required for the $M$ and the MA mode needs to be regenerated during the BER mode, or charged during the $\mathrm{CH}$ mode. To explain the basic principles of the RB EMS, which is a trade-off between energy balance and fuel consumption, consider the following two cases. Either case represents a different choice for $P^{o}{ }_{M}$, whereby the recuperated brake energy (BER) is: (i) not sufficient, and (ii) more than sufficient for supplying the energy during the motor only mode (M) over a given drive cycle.

(i) The additional required energy for the $\mathrm{M}$ mode has to be charged during the $\mathrm{CH} 1$ mode resulting in additional fuel cost.

(ii) The redundant energy of the BER mode can be used for motor-assisting during the MA1 mode resulting in additional fuel savings.

Both cases are schematically shown in the Fig. 3. Referring to case (i), if $-P^{o}{ }_{M}$ is lowered, then the additional fuel cost becomes lower due to decrease of the required charging energy. However, the fuel saving due to the $M$ mode is also reduced, and vice-versa, if $-P^{o}{ }_{M}$ is increased. The same holds for case (ii): the fuel saving during the MA1 mode is increased if $-P^{o}{ }_{M}$ is lowered, but the fuel saving due to the $M$ mode is reduced. For both cases, additional charging $(\mathrm{CH} 2$ mode) during driving and using for motor-assisting (MA2 mode) can be beneficial, if the energy is charged at a lower driving power, and this energy is used for motor-assisting at a higher driving power. However, the additional fuel saving is relatively small, because the drive energy at higher powers is relatively small. For more details concerning calculation of $P^{o}{ }_{M}$ is referred to [10].
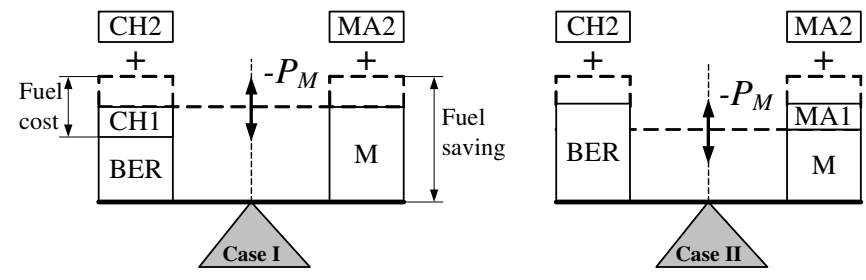

Fig. 3 Energy balance and fuel consumption

\subsection{Iterative Drivetrain Loss Compensation Procedure}

The operation points in the static-efficiency map of an engine, which maximizes the engine efficiency are collected by the Engine Optimal Operation Line (EOOL) for a given engine power $P^{o}{ }_{p}$ and secondary power $P_{s}$. The transmission efficiency $\eta_{t}=P_{v} / P_{p}^{o}$ is determined by the engine torque $T_{p}^{o}$ and speed $\omega_{p}$ (prescribed by the EOOL). However, the required $T_{p}^{o}$ and $\omega_{p}$ are determined by $\eta_{t}$ and the required $P_{v}$. Due to this causality conflict it is impossible to determine the $T_{p}^{o}$ and $\omega_{p}$ exactly. In this study the losses in $\mathrm{T}$ and $\mathrm{S}$ are iteratively estimated and are compensated for the engine power $P_{p}^{o}$. The error or the drivetrain loss in each iteration step is defined as,

$$
e(i) \triangleq\left|P_{p}^{o}(i+1)-P_{p}^{o}(i)\right|=P_{p}^{o}(i)\left(1-\eta_{t}\left(\omega_{p}^{o}(i), T_{p}^{o}(i)\right)\right)
$$

with iteration step $i \in \mathbb{N}$. The iteration is repeated until the error $e(i)$ between the iteration steps at a certain time instant becomes sufficiently small (i.e., $e(i) \leq \varepsilon$ ). In Fig. 4 the iterative procedure is schematically shown. A mathematical condition to prevent the iteration loop from instabilities, in terms of the estimation $P_{p}^{o}(i)$ is

$\left|P_{p}^{o}(i+1)-P_{p}^{o}(i)\right|<\gamma \cdot\left|P_{p}^{o}(i)-P_{p}^{o}(i-1)\right|, 0<\gamma<1$

This condition implies that error $e$ of each estimate decreases in each iteration step $i$. If the ratio of the error between the previous and the subsequent step becomes equal to 1 the estimates will not further improve. This corresponds with the transition between stable and unstable iteration loops. At later time instants the required $P^{o}$ can be calculated using the known values for the efficiencies at the previous time instant. Thereto, 
the requested $P_{v}$ is divided by the computed $\eta_{t}$. Using the modified $T_{p}^{o}$ and $\omega_{p}^{\rho}$ prescribed by the EOOL, which are stored-in look-up tables, the optimal power flow out $P_{s}$ is calculated using DP or the RB EMS given the drive cycle and the vehicle parameters.

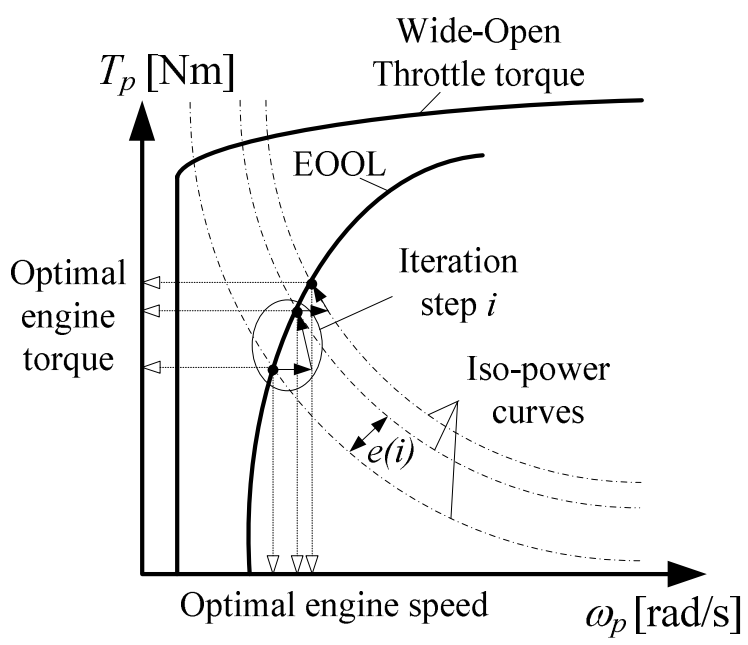

Fig. 4 Drivetrain loss compensation procedure

\subsection{Reference Control Models: ADVISOR and DP}

For comparison the control strategies as are implemented in ADVISOR are compared with the results from DP and the RB EMS. In Table 1 the rule-based conditions that define which hybrid mode is active for the different hybrid transmission types are given. Thereby, the battery is allowed to operate within a certain defined state-of-charge $\xi$ window, i.e., $\xi \in$ $\left[\xi_{\text {min }}, \xi_{\text {max }}\right]$. The control parameters as implemented in ADVISOR were optimized to achieve the highest fuel economy while the final $\xi\left(t_{f}\right)$ is maintained within a certain zero change in $\xi\left(t_{f}\right)+/-0.5 \%$ tolerance band. The optimizing torque fraction parameters $f_{l, j}$, power fraction parameters $f_{0, j}$ with $j \in\{1,2\}$ and the vehicle electric launch speed threshold value $v_{0}$ are intrinsic parameters of the control strategy. The parameters are used to assure that the engine is operated in the relative high efficiency areas. For details on these parameters and the functions for calculating the amount of charging/discharging power for the different topologies is referred to [2].

Table 1: ADVISOR rule-based control models

\begin{tabular}{l|l}
\hline \hline Mode: & Rule-based condition: \\
\hline BER & $\xi<\xi_{\text {max }} \cap T_{v}<0$ \\
$\mathrm{M}$ & $\xi \geq \xi_{\min } \cap\left\{P_{p}<f_{0,1} P_{p, \max } \cup\right.$ \\
& {$\left[T_{p}<f_{1,1} T_{p, \max }\left(\omega_{p}\right) \cup v<v_{0}(\xi)\right]^{*} \cup$} \\
& $\left.\left[v<v_{0}\right]^{* *}\right\}$ \\
$\mathrm{CH}$ & $\xi<\xi_{\min } \cup \xi<\xi_{\text {ref }} \cap$ \\
& $\left\{f_{0,1} P_{p, \max } \leq P_{p} \leq f_{0,2} P_{p, \max }\right\}$ \\
$\mathrm{E}$ & $\xi=\xi_{\text {ref }} \cap\left\{f_{0,1} P_{p, \max } \leq P_{p} \leq f_{0,2} P_{p, \max }\right\}$ \\
$\mathrm{MA}$ & $\xi \geq \xi_{\min } \cap\left\{P_{p}>f_{0,2} P_{p, \max } \cup\right.$ \\
& $\left.\left[T_{p}>T_{p, \max }\left(\omega_{p}\right)\right]^{*}, * *\right\}$ \\
\hline \hline
\end{tabular}

Additionally, in case of the * parallel transmission with CVT or the ${ }^{* *}$ series-parallel transmission
Using DP the finite horizon optimization problem is translated into a finite computation problem [10], [12]. Note that in principle the technique results in an optimal solution for the EMS, but that the grid step size also influences the accuracy of the result.

Furthermore, the engine and the generator of the series transmission are operated at the System Optimal Operation Line (SOOL). For the parallel transmission the electric machine and the engine are operated separately at the maximum efficiency points during the BER, $\mathrm{M}$ and the $\mathrm{E}$ mode (EOOL). During the $\mathrm{CH}$ and the MA mode the engine and the electric machine are operated at the SOOL. For the series-parallel transmission the engine is operated at the EOOL alone.

\section{RESULTS}

All simulations presented in this paper have been done on the JP10-15 drive cycle. The inertias of the electric machines, engine and auxiliary loads are, for simplicity, assumed to be zero. During braking energy is partially recuperated up to the maximum generative power limitation of the electric machine. In addition, some of the braking energy is dissipated between the front - and the rear-wheels in the wheel-brake discs. The braking energy distribution is prescribed by a non-linear function which is dependent on the vehicle speed [2]. During braking the engine is assumed to be shut-off or disengaged eliminating the engine drag losses. The Reference Vehicle (RV) is equipped with a 74-kW 1.6-L SI engine and a push-belt CVT as is used in the parallel transmission. In Table 6 an overview of the component data is given. The total power specification for every hybrid drivetrain configuration is kept constant at approximately $74 \mathrm{~kW}$. The battery pack is sized to meet the power specifications. In this way the dynamic performance of the vehicle is not compromised.

\subsection{Fuel Economy and Emissions}

In Table 2 the fuel economy and emission results for the different hybrid topologies and control models are listed. In Table 4 the characteristic parameters describing the $\mathrm{P}, \mathrm{S}$ and $\mathrm{T}$ efficiency, which are used with the RB EMS to calculate the fuel economy (test 12-14), are listed. Although the cost function consists only of the fuel consumption, for all hybrid drivetrains the $\mathrm{HC}, \mathrm{CO}$ and $N O_{x}$ emissions are reduced, except regarding the $N O_{x}$ emissions for the series transmission. This can be solved by using a weighted cost function consisting of the sum of the fuel use and emissions and increasing the weight factor regarding the $N O_{x}$ emissions. However, this has not been investigated in this paper. The relative influence of engine downsizing (without a battery), topology choice and hybridization (adding an S) on the fuel economy results is shown in Table 3. The lowest fuel economy is realized with the series-parallel transmission. Due to coupling of $S$ at the wheel-side of $\mathrm{T}$ for the series-parallel transmission (maximizing the regenerative brake efficiency) the fuel 
economy is lower than for the parallel hybrid transmission. In the Fig. 5 and Fig. 6 the energy distribution between different hybrid modes and the relative energy $\Delta E_{s}$ over time for the different topologies and strategies are shown respectively. Although, $S$ is coupled at the wheel-side of the transmission for both the series-parallel - and the series hybrid transmission, it can be seen, that the energy recuperation during braking (BER) for the series-parallel is larger than for the series. Since the $S$ efficiency of the series-parallel is higher than the $S$ efficiency of the series transmission. The series transmission has the highest fuel economy mainly due to the lowest transmission efficiency.

\subsection{Control Models Parameters - ADVISOR}

The fuel economy is mainly determined by the control constraints or rules, which determine where the engine is allowed to be turned off (BER and M mode). Therefore, the main control parameters within ADVISOR are $f_{0,1}, f_{1,1}$ or $v_{0}$ (see Table 1 ). The calibrated $f_{0,1}$ for each topology is also listed in Table 4 . Thereby, $f_{1,1} \geq f_{0,1}$ and $v_{0}$ is larger than the maximum cycle speed. The calibrated $f_{0,1}$ for the series transmission is 0.51 (equivalent to $P^{o}{ }_{M}=-32.5 \mathrm{~kW}$ ). At this power fraction the engine and generator are operated at the "sweet spot" of the engine (highest efficiency) and energy is charged with minimum fuel cost. However, with DP it was found that the fuel consumption could be reduced if the electric machine at the wheel-side is partially supplied by the battery up to a drive power of approximately $6.1 \mathrm{~kW}$. At higher power demands the battery power is augmented by power from the engine that is a function of the drive power $P_{v}$ and the state-of-charge $\xi$. It appeared to be not straightforward to adapt the defaults rules within ADVISOR by changing the main control parameters to the preferred optimal control settings. This explains the relative large discrepancy between DP and ADVISOR for the series transmission. Using the results from DP it showed that for the parallel and the series-parallel transmission the optimized $f_{0,1}$ are 0.10 (equivalent to $P^{o}{ }_{M}=-6.1 \mathrm{~kW}$ ) and 0.12 (equivalent to $P^{o}{ }_{M}=-7.5 \mathrm{~kW}$ ) respectively. With the default control parameters as implemented in ADVISOR for series-parallel transmission (Toyota Prius 1998) it was found that in the high-speed areas the engine was not allowed to shut off at relative low $P_{v}$ resulting in less Idle-Stop. In addition, generative torque of the motor during braking is reduced due to additional engine drag torque. Since, the vehicle speed was then larger than $v_{0}$. If $v_{0}$ is set to a larger value than the maximum cycle speed effectively more (free) energy is charged during the BER mode, which reduces the additional charging fuel cost. Furthermore, it was found that the optimal EMS is focused on charging during driving in the low-speed areas $(v<40 \mathrm{~km} / \mathrm{h})$ by the generator $(15-\mathrm{kW})$ and in the high-speed areas by the motor $(30-\mathrm{kW})$ respectively. This has influence on the optimal $P^{o}{ }_{M}$ as will be discussed in the following section.

\subsection{Parametric Efficiency Functions and Generic Hybrid Topology Model}

Although the static-efficiency map of the engine is very non-linear, the EOOL is well approximated by a quadratic fit function, i.e., $P_{f}=c_{2} \cdot P^{2}{ }_{p}+c_{1} \cdot P_{p}+c_{0}$ (for reasons of space this is not shown in this paper, e.g., see also [11]). In the Fig. 7 and Fig. 8 the linear functions fitted through the operation points for $S$ (BER and $M$ mode) and $\mathrm{T}$ (only $\mathrm{E}$ mode) are shown. For sake of clarity, the $\mathrm{S}$ efficiency for the parallel transmission as shown in Fig. 7 includes the $\mathrm{T}$ efficiency. The found component parameters including the calculated optimal control parameter $P^{o}{ }_{M}$ used in the RB EMS are shown in Table 4. In Fig. 7 also $P^{o}{ }_{M}$ is shown of tests 9, 10 and 11. Due to uncertainty on the found fit coefficients the static losses $c_{0}$ for $\mathrm{S}$ can be negative for positive output power and vice-versa.

The electric machines at the engine-side for the series - and the series-parallel transmission are assumed to be part of T. Furthermore, charging and motor-assisting during driving is only possible with the electric machines at the wheel side $(S)$. For the parallel transmission charging and motor-assisting during driving is done at the SOOL, which causes that the S efficiency is not similar to the $S$ efficiency during the BER and $M$ mode. These assumptions cause that the optimal $P^{o}{ }_{M}$ with the fit functions used with the generic hybrid topology model is higher than $P^{o}{ }_{M}$ with the actual drivetrain topology and component technology (see Table 4). Thereby, the energy charged and discharged during driving ( $\mathrm{CH}$ and $\mathrm{M}$ mode) is reduced (compare test 9-11 with test 12-14 in Fig. 5). However, the higher value for $P^{o}{ }_{M}$ for every hybrid drivetrain topology has a very small influence $(\sim 1 \%)$ on the overall fuel economy (compare test 9-11 with test 12-14 in Table 2).

The battery power influences the transmission efficiency. In Fig. 9, as example, the engine input power as function of the vehicle drive power for different battery powers calculated with DP for the series-parallel transmission is shown. However, the assumption of modeling the transmission efficiency used only in the $\mathrm{E}$ mode ("pure transmission efficiency") is allowable. The reason for this is: if the transmission input power is corrected with the battery power during the $\mathrm{CH}$ and the MA mode, then it can be seen that the "corrected hybrid transmission efficiency" is slightly better than the "pure transmission efficiency" (no battery power). However, the discrepancy is very small. Therefore, the difference in fuel economy is very small. This holds for every investigated topology (see Table 5). It can be concluded that the implicit sensitivity of the fit coefficients to battery power for $\mathrm{T}$ is small.

\section{CONCLUSIONS}

The results show that overall model simplification for the hybrid drivetrain topology, component technology and control strategy regarding fuel economy 
can be done with sufficient accuracy $(\sim 1 \%)$. Thereby, the component efficiencies and the control model are only described by $\mathrm{P}+\mathrm{S}+\mathrm{T}+\mathrm{C}=3+4+2+1=10$ characteristic parameters. In contrary to the relative large amount of required static component efficiency data and different control rules used in ADVISOR or the relative long computation time with DP. Determining the component parameters can be done in advance independent on the hybrid control strategy, but dependent on the choice of engine - or wheel-side coupling of $S$ to the drivetrain (topology choice), the vehicle load and speed. Reversibly, if realistic characteristic parameters for $\mathrm{P}, \mathrm{S}$ and $\mathrm{T}$ are determined fulfilling a certain fuel economy improvement; then component specifications (size and efficiency) can be derived and consequently the technology and topology can be selected or specified. In this way, control design, optimization, component and topology selection and specification are merged in a single methodology framework. In future work the design of a hybrid vehicle drivetrain (a passenger car - and a distribution truck case study) using the modeling approach as discussed in this paper will be investigated.

Table 2: Simulation results

\begin{tabular}{|c|c|c|c|c|c|}
\hline \multirow{2}{*}{ Test: } & \multirow{2}{*}{ Topology: } & \multirow{2}{*}{$\begin{array}{c}\text { Fuel } \\
\text { economy } \\
(1 / 100 \mathrm{~km})\end{array}$} & \multicolumn{3}{|c|}{ Emissions $[\mathrm{g} / \mathrm{km}] \dagger$} \\
\hline & & & $H C$ & $C O$ & $N O_{x}$ \\
\hline \multicolumn{6}{|c|}{ Simulink/ADVISOR (efficiency model: $\eta_{*}=\eta_{*}\left(T_{*}, \omega_{*}\right)$ ) } \\
\hline 1. & $\mathrm{RV} / 74-\mathrm{kW}$ & 8.24 & - & - & - \\
\hline 2. & $\mathrm{RV} / 43-\mathrm{kW}$ & 6.13 & 1.53 & 2.99 & 0.63 \\
\hline 3. & SE & 4.99 & 0.65 & 2.44 & 1.10 \\
\hline 4. & PA & 3.33 & 0.54 & 1.62 & 0.61 \\
\hline 5. & SP & 2.99 & 0.49 & 1.46 & 0.54 \\
\hline \multicolumn{6}{|c|}{ Dynamic Programming (efficiency model: $\eta_{*}=\eta_{*}\left(T_{*}, \omega_{*}\right)$ ) } \\
\hline 6. & SE & 3.88 & 0.48 & 1.64 & 0.68 \\
\hline 7. & PA & 3.08 & 0.48 & 1.50 & 0.59 \\
\hline 8. & SP & 2.96 & 0.45 & 1.39 & 0.53 \\
\hline \multicolumn{6}{|c|}{ Rule-Based EMS (efficiency model: $\eta_{*}=\eta_{*}\left(T_{*}, \omega_{*}\right)$ ) } \\
\hline 9. & SE & 3.89 & 0.52 & 1.88 & 0.82 \\
\hline 10. & PA & 3.07 & 0.48 & 1.49 & 0.58 \\
\hline 11. & SP & 2.98 & 0.46 & 1.46 & 0.56 \\
\hline \multicolumn{6}{|c|}{ Rule-Based EMS (efficiency model: $\eta_{*}=\eta_{*}\left(P_{*}\right)$, see Table 4) } \\
\hline 12. & SE & 3.90 & - & - & - \\
\hline 13. & PA & 3.04 & - & - & - \\
\hline 14. & SP & 2.93 & - & - & - \\
\hline
\end{tabular}

RV: Reference Vehicle; SE: Series; PA: Parallel;

SP: Series-Parallel. †at engine exhaust system, ${ }^{*}=\{\mathrm{p}, \mathrm{s}, \mathrm{t}\}$

Table 3: Relative fuel economy improvement

\begin{tabular}{cccc}
\hline \hline & $\begin{array}{c}\text { Series } \\
(1 / 100 \mathrm{~km})\end{array}$ & $\begin{array}{c}\text { Parallel } \\
(1 / 100 \mathrm{~km})\end{array}$ & $\begin{array}{c}\text { Series-parallel } \\
(1 / 100 \mathrm{~km})\end{array}$ \\
\hline A: Downsizing & $20.9 \%$ & $25.6 \%$ & $26.5 \%$ \\
& $(6.52)$ & $(6.13)$ & $(6.06)$ \\
B: Hybridization & $36.7 \%$ & $49.8 \%$ & $52.7 \%$ \\
& $(3.88)$ & $(3.08)$ & $(2.96)$ \\
\hline \hline
\end{tabular}

A:Reference test 1: $8.241 / 100 \mathrm{~km} /$

B:Reference test 2: $6.131 / 100 \mathrm{~km}$
Table 4: Model parameters ( Table 2, test 12-14)

\begin{tabular}{|c|c|c|c|c|}
\hline \multirow[b]{2}{*}{ Component models } & \multirow[b]{2}{*}{ Topology } & \multicolumn{3}{|c|}{ Model parameter } \\
\hline & & $\begin{array}{c}c_{2} \\
(1 / \mathrm{W})\end{array}$ & $\begin{array}{l}c_{1} \\
(-)\end{array}$ & $\begin{array}{c}c_{0} \\
(\mathrm{~W})\end{array}$ \\
\hline $\mathrm{P}(43-\mathrm{kW})(\mathrm{EOOL})$ & SE/PA/SP & $1.16 \mathrm{e}-5$ & 2.09 & 5194 \\
\hline S (BER mode) & SE & - & -0.75 & -73 \\
\hline $\mathrm{S}(\mathrm{M}$ mode $)$ & SE & - & -1.48 & -46 \\
\hline $\mathrm{T}$ (only E mode) & SE & - & 1.40 & 954 \\
\hline S (BER mode) & PA & - & -0.77 & -111 \\
\hline $\mathrm{S}$ (M mode ) & PA & - & -1.49 & 75 \\
\hline $\mathrm{T}$ (only E mode) & PA & - & 1.11 & 371 \\
\hline S (BER mode) & SP & - & -0.77 & 120 \\
\hline $\mathrm{S}(\mathrm{M}$ mode $)$ & SP & - & -1.43 & 48 \\
\hline $\mathrm{T}$ (only E mode) & SP & - & 1.11 & 192 \\
\hline Control model & Topology: & SE & PA & SP \\
\hline $\begin{array}{c}\text { C (ADVISOR, } \\
\text { test } 3-5)\end{array}$ & $f_{0, I} / P^{o}{ }_{M}$ & $\begin{array}{l}0.51 / \\
-32.5\end{array}$ & $\begin{array}{l}0.10 / \\
-7.5\end{array}$ & $\begin{array}{l}0.12 / \\
-6.1\end{array}$ \\
\hline $\mathrm{C}(\mathrm{RB}$, test $9-11)$ & $P_{M}^{o}(\mathrm{~W})$ & -9.0 & -7.0 & -7.0 \\
\hline $\mathrm{C}(\mathrm{RB}$, test $12-14)$ & $P_{M}^{o}(\mathrm{~W})$ & -6.0 & -6.0 & -6.0 \\
\hline
\end{tabular}

Table 5: Transmission efficiency parameters

\begin{tabular}{ccccccc}
\hline \hline & \multicolumn{2}{c}{ Series } & \multicolumn{2}{c}{ Parallel } & \multicolumn{2}{c}{ Series-Parallel } \\
\cline { 2 - 7 } Case: & $\begin{array}{c}c_{1} \\
(-)\end{array}$ & $\begin{array}{c}c_{0} \\
(\mathrm{~W})\end{array}$ & $\begin{array}{c}c_{1} \\
(-)\end{array}$ & $\begin{array}{c}c_{0} \\
(\mathrm{~W})\end{array}$ & $\begin{array}{c}c_{1} \\
(-)\end{array}$ & $\begin{array}{c}c_{0} \\
(\mathrm{~W})\end{array}$ \\
\hline $\begin{array}{c}\text { No battery } \\
\text { power }\end{array}$ & 1.40 & 954 & 1.11 & 371 & 1.11 & 192 \\
$\begin{array}{c}\text { With battery } \\
\text { power }\end{array}$ & 1.35 & 916 & 1.11 & 209 & 1.09 & 115 \\
\hline \hline
\end{tabular}

\section{NOMENCLATURE, ACONYMS, SYMBOLS}

Symbol Description

BER Brake-Energy Recovery mode

C Control model

$\mathrm{CH} \quad$ Charging mode

CVT Continuously Variable Transmission

DP Dynamic Programming

E Engine only mode

EM Electric Machine

EMS Energy Management Strategy

EOOL Engine Optimal Operation Line

M Motor only mode

MA Motor-Assist mode

P Primary power source (engine)

PA Parallel transmission

RB Rule-Based

RV Reference Vehicle

S Secondary power source

SE Series transmission

SP Series-Parallel transmission

T Transmission technology

Symbol Description Unit

$\begin{array}{lll}c_{2} & \text { Fit coefficient } & 1 / \mathrm{W}\end{array}$

$c_{1} \quad$ Fit coefficient - 


\begin{tabular}{|c|c|c|}
\hline$c_{0}$ & Fit coefficient & $\mathrm{W}$ \\
\hline$e$ & Error iteration step & W \\
\hline$f_{0,1}$ & Power ratio control parameter & $\mathrm{W} / \mathrm{W}$ \\
\hline$f_{0,2}$ & Power ratio control parameter & $\mathrm{W} / \mathrm{W}$ \\
\hline$f_{1,1}$ & Torque ratio control parameter & $\mathrm{Nm} / \mathrm{Nn}$ \\
\hline$g$ & Inequality constraints & $\mathrm{W}$ \\
\hline$h$ & Equality constraints & $\mathrm{J}$ \\
\hline$i$ & Iteration step & - \\
\hline$t$ & Time & $\mathrm{s}$ \\
\hline$t_{f}$ & Final time & $\mathrm{s}$ \\
\hline$v$ & Vehicle speed & $\mathrm{m} / \mathrm{s}$ \\
\hline$v_{0}$ & Vehicle speed threshold value & $\mathrm{m} / \mathrm{s}$ \\
\hline$E_{*}$ & Energy level & $\mathrm{J}$ \\
\hline$J$ & Fuel energy & $\mathrm{J}$ \\
\hline$P_{*}$ & Power & $\mathrm{W}$ \\
\hline$T_{*}$ & Output torque & $\mathrm{Nm}$ \\
\hline$\gamma$ & Convergence ratio & - \\
\hline$\eta_{*}$ & Component efficiency & - \\
\hline$\omega_{*}$ & Angular speed & $\mathrm{rad} / \mathrm{s}$ \\
\hline$\xi_{*}$ & State-of-Charge & - \\
\hline \multicolumn{3}{|c|}{$($ Sup-)Subscripts $(*)$} \\
\hline Symbol & \multicolumn{2}{|l|}{ Description } \\
\hline em & \multicolumn{2}{|l|}{ Electric machine } \\
\hline$f$ & \multicolumn{2}{|l|}{ Fuel } \\
\hline$o$ & \multicolumn{2}{|l|}{ Optimal value } \\
\hline$p$ & \multicolumn{2}{|l|}{ Primary source (engine) } \\
\hline & \multicolumn{2}{|c|}{ Secondary source (battery/electric machine) } \\
\hline & \multicolumn{2}{|l|}{ Transmission technology } \\
\hline & \multicolumn{2}{|l|}{ Vehicle wheels } \\
\hline$M$ & \multicolumn{2}{|l|}{ Motor power threshold value } \\
\hline $\min$ & \multicolumn{2}{|l|}{ Minimum value } \\
\hline $\max$ & \multicolumn{2}{|l|}{ Maximum value } \\
\hline re & \multicolumn{2}{|l|}{ Reference value } \\
\hline
\end{tabular}

\section{REFERENCES}

[1] B.K. Powell, K.E. Bailey, and S.R. Cikanek: "Dynamic Modeling and Control of Hybrid Electric Vehicle Powertrain Systems", In: IEEE-Control Syst. Mag., Vol.18, No.5, pp.17-33, 1998.

[2] K.B. Wipke, M.R. Cuddy, and S.D. Burch: "ADVISOR 2.1: A User-Friendly Advanced Powertrain Simulation Using a Combined Backward/Forward Approach", In: IEEE-Transactions on Vehicular Technology, Vol.48, pp.1751-1761, $1999 . \quad$ Available at http://www.ctts.nrel.gov/analysis/.

[3] K.L. Butler, M. Ehsani, and P. Kamath: "A Matlab-Based Modeling and Simulation Package for Electric and Hybrid Electric Vehicle Design", In: IEEE-Transactions on Vehicular Technology, Vol.48, pp.1770-1778, 1999.

[4] G. Rizzoni, L. Guzzella, and B. M. Baumann: "Unified Modeling of Hybrid Electric Vehicle Drivetrains", In: IEEE-Transactions on Mechatronics, Vol.4, No.3, pp.246-257, 1999.

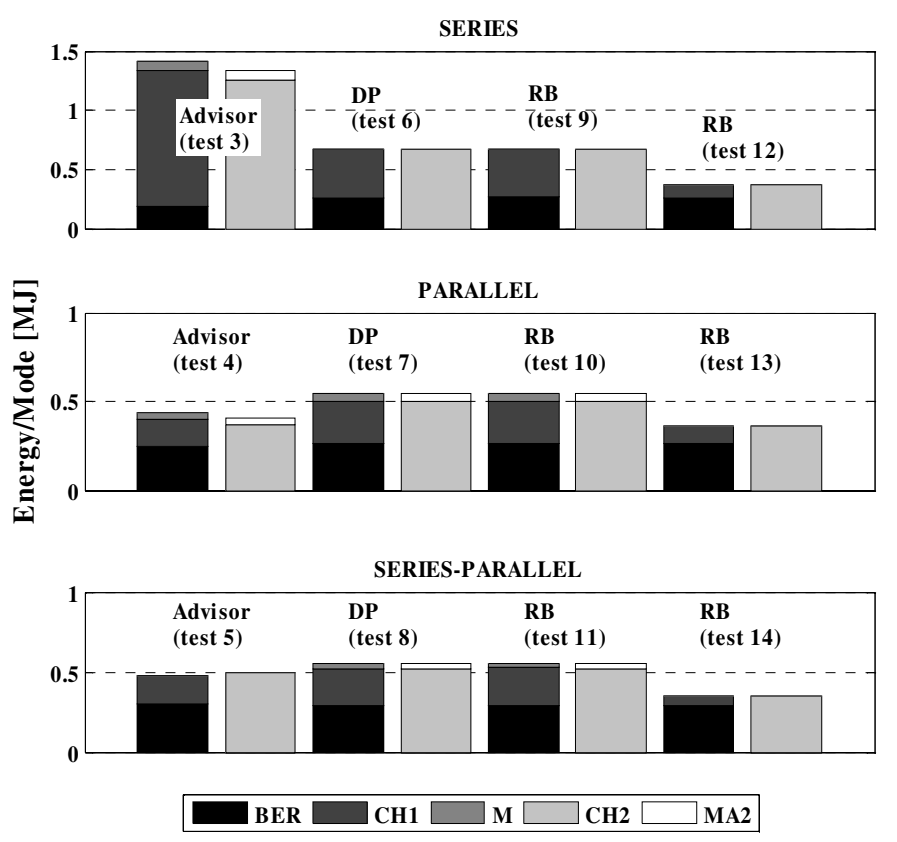

Fig. 5 Energy distribution over the hybrid modes

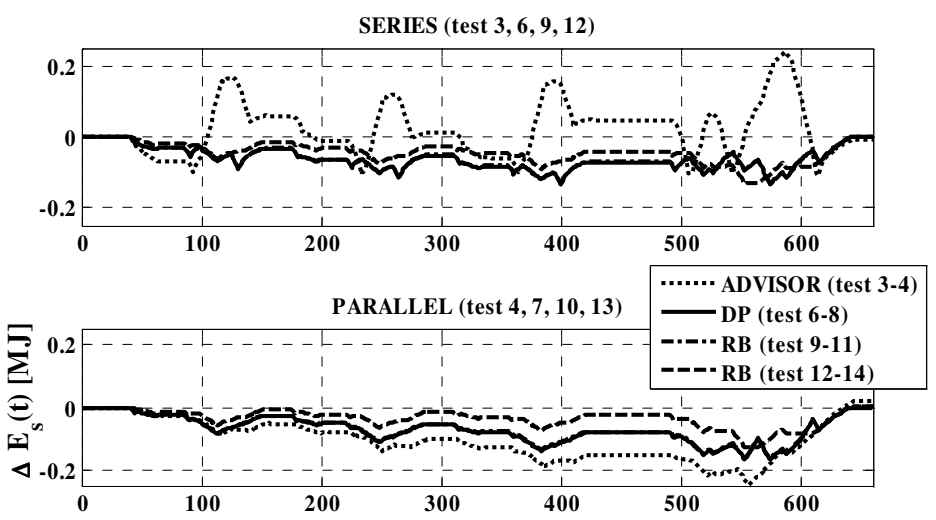

SERIES-PARALLEL (test $5,8,11,14$ )

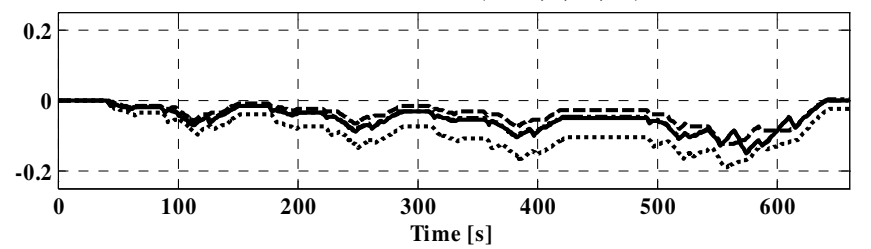

Fig. 6 Relative energy over time 


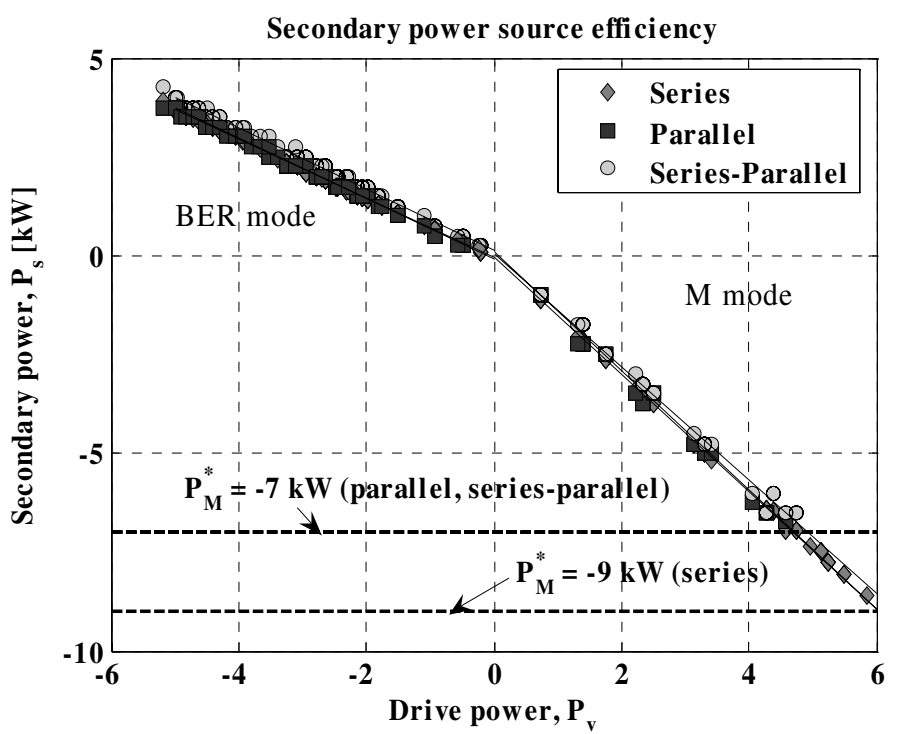

Fig. 7 Output power as a function of the input power for $\mathrm{S}$ (during the BER/M mode)

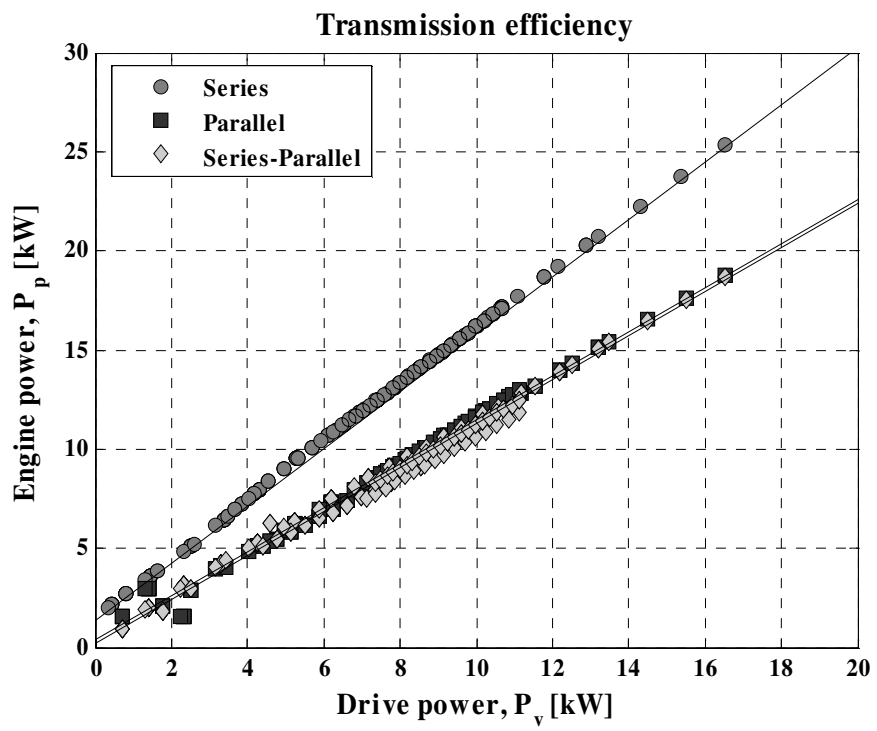

Fig. 8 Output power as a function of the input power for $\mathrm{T}$ (pure transmission efficiency, only $\mathrm{E}$ mode)

[5] L. Guzzella, and A. Amstutz: "CAE Tools for Quasi-Static Modeling and Optimization of Hybrid Powertrains", In: IEEE-Transactions on Vehicular Technology, Vol.48, No.6, pp.1762-1769, 1999.

[6] D. Assanis, G. Delagrammatikas, R. Fellini, Z. Fillipi, J. Liedtke, N. Michelena, P. Papalambros, D. Reyes, D. Rosenbaum, A. Sales, and M. Sasena: "Optimization approach to hybrid electric propulsion system design", In: J. of Mech. Struct. \& Mach., Vol.27, No.4, pp.393-421, 1999.

[7] A. Molyneaux, G. Leyland, and D. Favrat: "Multi-objective optimisation of vehicle drivetrains", In: Proc. of Swiss Transport Research Conference, Monte Verita, Ascona, 2003.

[8] J. Scordia, M. Desbois Renaudin, R. Trigui, B. Jeanneret, F. Badin, and C. Plasse: "Global optimization of energy management laws in hybrid vehicles using dynamic programming". In: Int. J. of Vehicle Design, Vol.39, No.4, pp.349-367, 2005

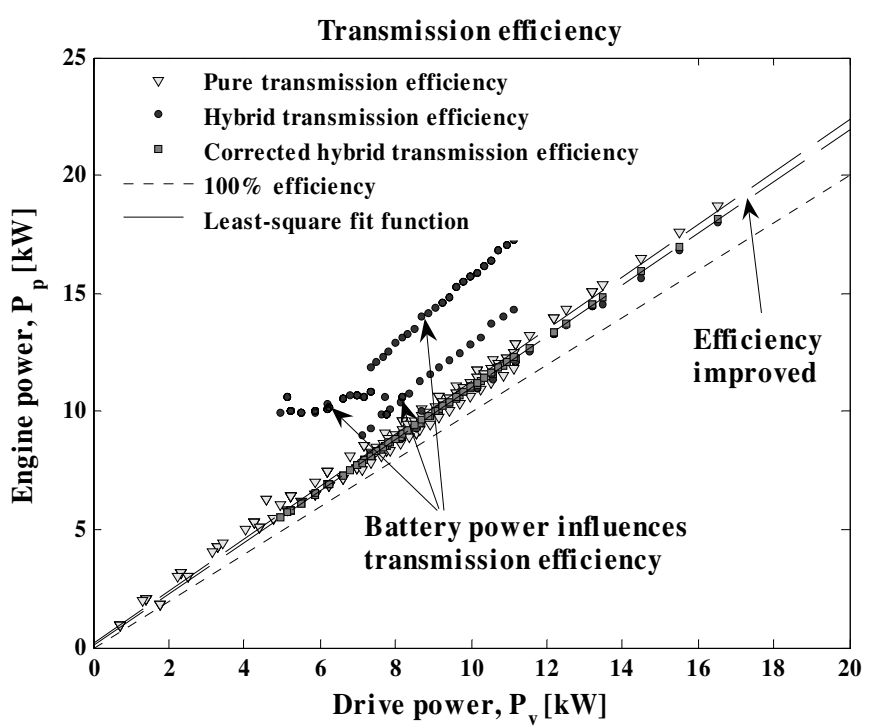

Fig.9 Influence of battery power on transmission efficiency (all hybrid modes are active)

[9] M. Koot, J. Kessels, A. de Jager, W. Heemels, P. van den Bosch and M. Steinbuch: "Energy management strategies for vehicular power systems", In: IEEE-Transactions on Vehicular Technology, Vol.54, No.3, pp.771-782, 2005.

[10] T. Hofman, M. Steinbuch, A. Serrarens, and R. van Druten: "Rule-based energy management strategies for hybrid vehicle drivetrains: A fundamental approach in reducing computation time", In: Proc. of 4th IFAC-Symposium on Mechatronic Systems, Heidelberg, Germany, 2006.

[11] T. Hofman, M. Steinbuch, and R. van Druten: "Modeling for simulation of hybrid drivetrain components", In: Proc. of IEEE-Symposium on Vehicular Propulsion and Power, London, UK, 2006.

[12] R.E. Bellman: "Dynamic programming", Princeton University Press, 1962.

\section{BIOGRAPHIES}

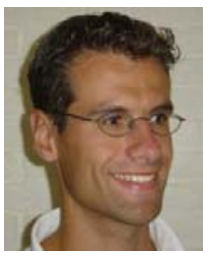

Theo Hofman studied Mech. Eng. at the Technische Universiteit Eindhoven (TU/e). Since August 2003, he is a Ph.D. candidate with the Control Systems Technology group. His research interests are modeling, design and control of hybrid vehicle powertrains.

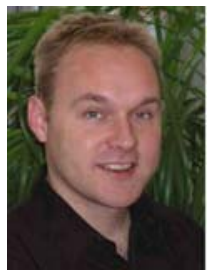

Alex Serrarens was born 6 september 1973 in Hulst, The Netherlands. $\mathrm{He}$ received his MSc-degree MechEng in april 1997 at the Technische Universiteit Eindhoven. In 2001 he received his $\mathrm{PhD}$ degree from the same university in the field of powertrain control of passenger cars with CVT. Currently he is business partner within Drivetrain Innovations (DTI) which is a licensing and contract-research center on automotive powertrains, transmissions and components. 


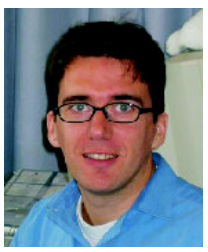

Roëll van Druten finished his Masters in June 1996 and his Ph.D. in October 2001, both at the Technische Universiteit Eindhoven. Currently he is a CEO of Drivetrain Innovations (DTI), which is a licensing and contract-research center on automotive powertrains, transmissions and components.

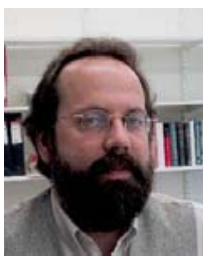

Maarten Steinbuch is received his $\mathrm{MSc}$ and $\mathrm{PhD}$ degree from Delft University of Technology, Delft, The Netherlands, in 1984 and 1989 respectively. From 1987 to 1999 he was researcher and groupleader with Philips Electronics. Since 1999 he has been a full professor of the Control Systems Technology group of the Mechanical Engineering Department of Eindhoven University of Technology. Since 2006 he is also Scientific Director of the 3TU Centre of Competence High Tech Systems.

\section{ACKNOWLEDGEMENT}

This study is part of "Impulse Drive" which is a research project at the Technische Universiteit Eindhoven in The Netherlands within the section Control Systems Technology of the Department of Mechanical Engineering. The project is financially supported by the NWO Technology Foundation within the Innovation Research Incentives Scheme 2000/2001.

Table 6: Component data for hybrid drivetrains

Series transmission

\begin{tabular}{l|l}
\hline $\begin{array}{l}\text { Electric machine } \\
\text { (wheel side) }\end{array}$ & $\begin{array}{l}\text { Manufacturer: Westinghouse; 75-kW (continuous) AC induction motor/inverter, Torque range: from 271 } \\
{[\mathrm{Nm}] \text { to } 72[\mathrm{Nm}] \text { (corresponding speed from 0 [rpm] to 10000 [rpm]). The efficiency map includes the }} \\
\text { inverter/controller efficiencies. (Data file ADVISOR: MC_AC76) } \\
\begin{array}{l}\text { Electric machine } \\
\text { (engine side) }\end{array}\end{array}$ \\
$\begin{array}{l}\text { Manufacturer: Mannesmann Sachs; 63-kW (continuous) PM motor/inverter, Torque range: from 157 [Nm] } \\
\text { to } 110[\mathrm{Nm}] \text { (corresponding speed from 0 [rpm] to 5500 [rpm]). The efficiency map includes the } \\
\text { inverter/controller efficiencies. (Data file ADVISOR: GC_PM63) } \\
\text { The final drive ratio is 6.79 [-] with a constant efficiency of 0.98 [-] }\end{array}$ \\
\hline
\end{tabular}
Parallel transmission

Electric machine $\quad$ Manufacturer: Toyota; 30-kW (continuous) PM motor/inverter, Torque range: from 305 [Nm] to 47.7

(engine side) $\quad[\mathrm{Nm}]$ (corresponding speed from $0[\mathrm{rpm}]$ to $6000[\mathrm{rpm}]$ ). The efficiency map includes the inverter/controller efficiencies. (Data file ADVISOR: MC_PRIUS_JPN)

CVT/final drive The push-belt CVT has an under-drive and over-drive ratio of 2 [-] and 0.4 [-] respectively. The final-drive ratio is 5.83 [-]. The efficiency map includes the final drive efficiency.

(Data file ADVISOR: TX_CVT50_SUBARU)

$$
\text { Series-Parallel transmission }
$$

Electric machine $\quad$ Manufacturer: Toyota; $15-\mathrm{kW}$ (continuous) PM motor/inverter, Torque range: from 55 [Nm] to 26 [Nm] (engine side) (corresponding speed from $0[\mathrm{rpm}]$ to $5500[\mathrm{rpm}]$ ). The efficiency map includes the inverter/controller efficiencies. (Data file ADVISOR: GC_PRIUS_JPN)

Electric machine $\quad$ Manufacturer: Toyota; 30-kW (continuous) PM motor/inverter, Torque range: from 305 [Nm] to 47.7 (wheel side) $\quad[\mathrm{Nm}]$ (corresponding speed from $0[\mathrm{rpm}]$ to $6000[\mathrm{rpm}]$ ). The efficiency map includes the inverter/controller efficiencies. (Data file ADVISOR: MC_PRIUS_JPN)

Planetary gear $\quad$ The planetary gear set ratio and the final drive ratio are $-2.6[-]$ and $3.93[-]$ respectively. The efficiencies set/Final drive $\quad$ are both constant 0.98 assumed. Energy storage system

\begin{tabular}{|c|c|}
\hline Battery pack & $\begin{array}{l}\text { Manufacturer: Panasonic; Type: Ni-MH, Nominal voltage } 288[\mathrm{Vdc}], \text { Capacity } 6[\mathrm{Ah}] ; \xi_{\min }=0.30[-] ; \\
\xi_{\max }=0.80[-] ; \xi_{\text {ref }}=0.55[-] . \text { (Data file ADVISOR: ESS_NIMH6) }\end{array}$ \\
\hline \multicolumn{2}{|r|}{ Vehicle data } \\
\hline \multicolumn{2}{|c|}{$\begin{array}{l}\text { Mass: } 1368[\mathrm{~kg}] \text {, Air drag coefficient: } 0.29 \text { [-], Frontal area: } 1.746[\mathrm{~m} 2] \text {, Roll resistance coefficient: } 0.9 \text { [\%], Maximum } \\
\text { regenerative brake fraction: } 0.5[-] \text {. (Data file ADVISOR: VEH_PRIUS_JPN) }\end{array}$} \\
\hline \multicolumn{2}{|r|}{ Engine data } \\
\hline
\end{tabular}

